\title{
Commentary Immunosedation: a consideration for sepsis
}

\author{
Robert MacLaren
}

University of Colorado Denver School of Pharmacy, Academic Office 1, C238-L15, 12631 East 17th Avenue, Aurora, CO 80045, USA

Corresponding author: Robert MacLaren, rob.maclaren@ucdenver.edu

Published: 6 October 2009

This article is online at http://ccforum.com/content/13/5/191

(c) 2009 BioMed Central Ltd

See related research by Qiao et al., http://ccforum.com/content/13/4/R136
Critical Care 2009, 13:191 (doi:10.1186/cc8034)

ing that neural-immune modulation involving alpha-2 stimulation is essential to the anti-inflammatory mechanism of dexmedetomidine [2]. Of note, iNOS expression is enhanced at supratherapeutic concentrations of dexmedetomidine and further suggests that alpha-2 selectivity contributes to the anti-inflammatory action of dexmedetomidine [2]. Perhaps most intriguing is that hemodynamic stability and short-term survival rate emulate the dose-dependent and timedependent anti-inflammatory effects of dexmedetomidine in these animal models of sepsis [3-5].

Benzodiazepines have also demonstrated dose-dependent suppression of COX-2, iNOS, and pro-inflammatory mediators in models of sepsis [6-10]. These studies suggest that the mechanism is mediated by inhibiting nuclear translocation of nuclear factor-kappa-B, reducing phosphorylation of p38 mitogen-activated protein, and stabilizing mast cells. The results of animal studies have shown conflicting outcomes with benzodiazepines, in contrast to dexmedetomidine, as survival rate is lower and organ function unaffected but bactericidal effect enhanced with benzodiazepine therapy [10].

Few studies have investigated the immunomodulating effects of sedatives in critically ill patients. In surgical patients, dexmedetomidine 0.2 to $2.5 \mu \mathrm{g} / \mathrm{kg}$ per hour reduced IL-6 over the course of an 8-hour period to a greater extent than propofol 1 to $3 \mathrm{mg} / \mathrm{kg}$ per hour [11]. Also in surgical patients, midazolam 0.02 to $0.06 \mathrm{mg} / \mathrm{kg}$ per hour reduced TNF- $\alpha$, $\mathrm{IL}-1 \beta$, and IFN- $\gamma$ after 48 hours whereas propofol 0.5 to $1.5 \mathrm{mg} / \mathrm{kg}$ per hour increased the production of these proinflammatory cytokines [12]. A direct comparison of dexmedetomidine 0.2 to $2.5 \mu \mathrm{g} / \mathrm{kg}$ per hour and midazolam 0.1 to $0.5 \mathrm{mg} / \mathrm{kg}$ per hour in septic patients showed that only dexmedetomidine suppressed the expression of TNF- $\alpha$, $\mathrm{IL}-1 \beta$, and IL-6; however, both agents improved oxygenation

COX-2 = cyclooxygenase-2; IFN- $\gamma=$ interferon-gamma; IL $=$ interleukin; iNOS $=$ inducible nitric oxide synthase; TNF- $\alpha=$ tumor necrosis factoralpha. 
as assessed by gastric mucosal $\mathrm{pH}$ [13]. In a subgroup of 39 septic patients from the MENDS (maximizing efficacy of targeted sedation and reducing neurological dysfunction) trial, the risk of dying was lower in the group that received dexmedetomidine compared with lorazepam (hazard ratio $=$ $0.3,95 \%$ confidence interval $=0.1$ to $0.9, P=0.036$ ) [14]. The SEDCOM (Safety and Efficacy of Dexmedetomidine Compared With Midazolam) study compared dexmedetomidine and midazolam and reported a lower overall infection rate in the dexmedetomidine group $(10.2 \%$ versus $19.7 \%$, $P=0.02$ ), but this may be attributed to a shorter ventilator requirement in this group rather than different immunomodulating properties of the sedatives [15]. Mortality rates at day 30 were similar between groups.

Should a particular class of sedative be preferred when sedating the septic patient? At present, the answer to this question is 'no' or at least 'not yet'. What is evident is that sedatives have immunomodulating properties and that autonomic activity influences cytokine expression. Indeed, adrenergic catecholamines are known to influence immune responses and the process of inflammation [16]. Animal models of sedatives in sepsis rarely administered vasopressors for hemodynamic support, but it is conceivable that a particular vasopressor-sedative combination may be preferentially chosen to counterbalance their immunomodulating effects or enhance a specific effect. Septic patients frequently receive other immunomodulating therapies, including corticosteroids, drotrecogin, opioid analgesics, propofol, or immunonutrients $[17,18]$. How these agents interact with alpha-2 agonists or benzodiazepines is unknown, but presumably the use of these modalities was distributed equally in the few clinical studies conducted to date. Hypotension is a particular concern of using an alpha-2 agonist in sepsis. Data from animal studies, however, demonstrate improved hemodynamic profiles as the pro-inflammatory process subsides with dexmedetomidine administration [3-5].

Whether sedatives possess dose-dependent immunomodulating effects has not been studied in critically ill patients. Animal data, however, suggest that dexmedetomidine may possess an optimal dose for its immunomodulating activity [3-5]. This dose would likely vary between patients and within the same patient over time. The logical question if such a dose does exist is what to do if additional sedation is required. Or is this, in addition to shorter ventilator requirements and improved neurologic recovery, justification for minimizing sedation? Another intriguing observation is the time-dependent immunomodulating effect of dexmedetomidine because, in theory, dexmedetomidine may be an ideal sedative to initiate in early sepsis but other sedatives may be preferred later [3-5]. Does this necessitate changing the sedative agent as the sepsis process progresses? This is not unlike the scenario of the patient perceived to be unresponsive to a particular antibiotic who is changed to another class of antibiotic for greater response. Obviously, these queries are speculative. The studies conducted to date in animal models of sepsis show that there are disparate immunomodulating effects and possibly therapeutic outcomes between sedatives [1-17]. Perhaps one day the choice of sedative in septic patients will not be based solely on sedative properties but rather immunosedative profiles.

\section{Competing interests}

RM has received grant funding from Hospira, Inc. (Lake Forest, IL, USA).

\section{References}

1. Qiao H, Sanders RD, Ma D, Wu X, Maze M: Sedation improves early outcomes in severely septic Sprague Dawley rats. Crit Care 2009, 13:R136.

2. Lai YC, Tsai PS, Huang CJ: Effects of dexmedetomidine on regulating endotoxin-induced up-regulation of inflammatory molecules in murine macrophages. J Surg Res 2009, 154:212219.

3. Taniguchi T, Kidani $\mathrm{Y}$, Kanakura H, Takemoto $\mathrm{Y}$, Yamamoto K: Effects of dexmedetomidine on mortality rate and inflammatory responses to endotoxin-induced shock in rats. Crit Care Med 2004, 32:1322-1326.

4. Hofer S, Steppan J, Wagner T, Funke B, Lichtenstern C, Martin E, Graf BM, Bierhaus A, Weigand MA: Central sympatholytics prolong survival in experimental sepsis. Crit Care 2009, 13:R11.

5. Taniguchi T, Kurita A, Kobayashi K, Yamamoto K, Inaba H: Doseand time-related effects of dexmedetomidine on mortality and inflammatory responses to endotoxin-induced shock in rats. $J$ Anesth 2008, 22:221-228.

6. Kim SN, Son SC, Lee SM, Kim CS, Yoo DG, Lee SK, Hur GM, Park JB, Jeon $\mathrm{BH}$ : Midazolam inhibits proinflammatory mediators in the lipopolysaccharide-activated macrophage. Anesthesiology 2006, 105:105-110.

7. Bidri M, Royer B, Averlant G, Bismuth G, Guillosson JJ, Arock M: Inhibition of mouse mast cell proliferation and proinflammatory mediator release by benzodiazepines. Immunopharmaco/ogy 1999, 43:75-86.

8. Galley HF, Dubbels AM, Webster NR: The effect of midazolam and propofol on interleukin-8 from human polymorphonuclear leukocytes. Anesth Analg 1998, 86:1289-93.

9. Goto Y, O'Malley C, Fanning NF, Wang J, Redmond HP, Shorten GD: Benzodiazepines inhibit the rate of neutrophil apoptosis. Ir J Med Sci 2003, 172:191-194.

10. Tsao CM, Wu CC, Liaw WJ, Ho ST: Effects of midazolam on organ dysfunction in rats with endotoxemia induced by lipopolysaccharide. Acta Anaesthesiol Taiwan 2009, 47:10-16.

11. Venn RM, Bryant A, Hall GM, Grounds RM: Effects of dexmedetomidine on adrenocortical function, and the cardiovascular, endocrine and inflammatory responses in postoperative patients needing sedation in the intensive care unit. $\mathrm{Br} J$ Anaesth 2001, 86:650-656.

12. Helmy SAK, Al-Attiyah RJ: The immunomodulatory effects of prolonged intravenous infusion of propofol versus midazolam in critically ill surgical patients. Anaesthesia 2001, 56:4-8.

13. Memis D, Hekimoglu S, Vatan I, Yandim T, Yüksel M, Süt N: Effects of midazolam and dexmedetomidine on inflammatory responses and gastric intramucosal $\mathrm{pH}$ to sepsis in critically ill patients. Br J Anaesth 2007, 98:550-552.

14. Pandharipande P, Girard TD, Sanders RD, Thompson JL, Maze M, Ely EW: Comparison of sedation with dexmedetomidine versus lorazepam in septic ICU patients. Crit Care 2008, 12 (Suppl 2):P275.

15. Riker RR, Shehabi Y, Bokesch PM, Ceraso D, Wisemandle W, Koura F, Whitten P, Margolis BD, Byrne DW, Ely EW, Rocha MG; SEDCOM (Safety and Efficacy of Dexmedetomidine Compared With Midazolam) Study Group: Dexmedetomidine vs midazolam for sedation of critically ill patients: a randomized trial. JAMA 2009, 301:489-499.

16. Flierl MA, Rittirsch D, Huber-Lang M, Sarma JV, Ward PA: Catecholamines-crafty weapons in the inflammatory arsenal of immune/inflammatory cells or opening pandora's box? Mol Med 2008, 14:195-204. 
17. Sanders RD, Hussell T, Maze M: Sedation and immunomodulation. Crit Care Clin 2009, 25:551-570.

18. Webster NR, Galley HF: Immunomodulation in the critically ill. Br J Anaesth 2009, 103:70-81. 